\title{
ASSESSMENT OF EARTHQUAKE-INDUCED DAMAGE LEVEL ON BUILDINGS: ANALYSIS OF TWO DIFFERENT SURVEY METHODS FOR A CASE STUDY
}

\author{
V. Croce ${ }^{1 *}$, G. Caroti ${ }^{1}$, A. Piemonte ${ }^{1}$ \\ ${ }^{1}$ Civil and Industrial Engineering Department (DICI), A.S.T.R.O. Laboratory, University of Pisa \\ Largo Lucio Lazzarino 1, 56122 Pisa, Italy - (valeria.croce@unifi.it; gabriella.caroti, andrea.piemonte@ing.unipi.it)
}

Commission II, WG II/8

KEY WORDS: Seismic Damage, Natural Hazard, Seismic Assessment, UAVs, Post-catastrophe surveying

\begin{abstract}
:
Purpose of this paper is to compare different methods for the assessment of earthquake-induced damage on buildings based on survey data, referring to the case study of Castelluccio di Norcia. The seismic events that occurred in Central Italy in 2016 threatened the future of many villages located along the Apennine ridge straddling the Regions of Umbria, Marche, Abruzzo and Lazio: in Castelluccio di Norcia, a minor historical center in the Municipality of Norcia (Umbria), the earthquake occurred on August the $24^{\text {th }}$ caused some damage on localized buildings, but the strongest seismic event -the one occurred on October the $30^{\text {th }}$ and with magnitude $\mathrm{M}_{\mathrm{w}} 6.5$, provoked numerous collapses and widespread failure on several buildings of the village, razing to the ground almost the $60 \%$ of the built heritage. After the two earthquakes respectively, the Fire Brigade organized a reconnaissance campaign and flew over the village via UAVs (Unmanned Aerial Vehicles). By acquiring the videos recorded in this framework, that are currently available on the net and originally not recorded for specific survey purposes, the authors produced 3D models of the village allowing to compare the configuration of Castelluccio in the phases pre- and post- the destructive event of $30^{\text {th }}$ October: in fact, since the level of damage after the earthquake of August the $24^{\text {th }}$ was very low, the model resulting from the video recorded after this earthquake could be used as a model showing the layout of the village before the main struck of October. The result of this study is the Damage Degree Evaluation (DDE) and the following definition of a map showing for each building its class of damage, according to the distinction provided by European Macro-seismic Scale EMS98. On the other hand, another damage level map was studied: the Civil Protection requested, immediately after the earthquake and for the management of disaster response activities, the activation of the COPERNICUS project, providing for the detection of most damaged buildings of the village for an early census of the non-safe areas. The map of the damage level produced within this project is of course more accurate and precise, since it was collected through different acquisition systems: UAV, close-range photogrammetry, LiDAR (Light Detection And Ranging) and SLAM (Simultaneous Location and Mapping)-based mapping. This paper proposes a comparison between the two different DDEs, in order to define whether the first method, even if based on data downloaded via the web and therefore at lower resolution, and even if acquired with a more rapid evaluation procedure not providing for ground-based surveys, can lead to the construction of damage level maps that are plausible and realistic. The question is if the first method of DDE, even if less accurate, can allow to obtain results that are satisfactory and useful in the process of management and monitoring of natural hazards, providing support for the several implied institutions, in terms of information on catastrophes and first disaster rescue management.
\end{abstract}

\section{INTRODUCTION}

The paper compares two different maps based on Damage Degree Evaluation (DDE) produced with two different survey procedures for the post-seismic assessment of Castelluccio di Norcia, a village of the Municipality of Norcia, Umbria Region, which was hit by the $\mathrm{M}_{\mathrm{w}} 6.5$ earthquake, occurred in Central Italy, along the territories of the Apennine ridge, in year 2016.

Nowadays, Disaster Management (DM) techniques are more and more studied within the field of research of Geomatics: information on the impact of a certain natural hazard and on disaster rescue management can be acquired starting from data surveying and processing.

For emergency mapping, recent researches have shown the importance of the applicability of endorsed survey procedures and have revealed the necessity of $3 \mathrm{D}$ data processing and validation as a support for stakeholders in disaster monitoring and management [Caroti et al, 2017a]; the traditional survey methods, if implied in hazardous situations, appear to be timeconsuming and present difficulties related to the need to have a ground-based inspection.

In recent years, concerning the topographic surveying and the studies on geomatics, techniques of different kinds have been tested in studies on disaster risk management, with diverse types of outputs and levels of accuracy [Caroti et al, 2018a; Caroti et

* Corresponding author al, 2018b]: remote-sensing techniques have been considered as a fundamental support instrument in building damage assessment [Alicandro and Rotilio, 2019; Remondino et al., 2016; Boccardo and Giulio Tonolo, 2015]. Aerial images, particularly, offer a crucial aid in damage detection after a catastrophic event. In postcatastrophe scenarios, in fact, the use of drones, also referred to as UAVs (Unmanned Aerial Vehicles) is continuously showing its advantages, allowing to have immediate aerial information on the state of damage and overcoming the difficulties related to the inaccessibility of disrupted areas and to the impossibility to carry out on-site inspections [Bevilacqua et al., 2018; Caroti et al., 2015]. As part of the topographic survey, access to spatial data on a given built area allows to reconstruct three-dimensional models that can be fundamental and helpful in the analysis of post-catastrophe scenarios; in particular, purpose of this paper is to compare the results obtained, in terms of assessment of the damage level, starting from two different survey procedures that were applied to the case study of Castelluccio di Norcia after the disruptive earthquake of $30^{\text {th }}$ October 2016.

On one hand, in fact, an accurate survey procedure was applied immediately after the seismic event in the framework of the COPERNICUS EMS (Emergency Management Service) project [http://www.copernicus.eu/sites/default/files/documents/Copern icus_Factsheets/Copernicus_EmergencyMonitoring_Feb2017.p $\mathrm{df}]$, that was aimed at the management of disaster response 
activities and involved the combined use of different acquisition systems, such as UAV, close-range photogrammetry, LiDAR (Light Detection And Ranging) and SLAM (Simultaneous Location and Mapping)-based mapping [Havas, C. et al., 2018]. On the other hand, a more rapid and simplified method was applied by Croce and Martínez-Espejo Zaragoza (2018), based on videos made by the Fire Brigade through the use of UAVs and downloadable via web, originally not recorded for specific survey purposes but only registered in the framework of a reconnaissance campaign aimed at knowing the extent of damage on buildings.

Considering the fact that both the survey procedures led to the definition of damage level maps, this study aims to establish the goodness and accuracy of the second method, that represent a simplified procedure of Damage Degree Evaluation (DDE), in comparison with the one resulting from COPERNICUS EMS project survey campaigns, and to investigate how, after the occurrence of a catastrophic event, it is possible to acquire information on the affected areas, by accessing data uploaded on the web.

In this sense, digital information technologies represent a powerful supporting tool in the management of natural and manmade disasters.

\section{GEOMATICS APPLIED TO DISASTER MANAGEMENT}

Following the occurrence of strong seismic events, such as those ones that took place during the year 2016 in Central Italy, along the Apennine ridge, the issues concerning the importance of applying the discoveries and innovative features of geomatics researches to the field of rapid mapping arose again [Caroti et al., 2017b]. In fact, in order to manage the emergency phases, to arrange safety and recovery measures and to decide which areas were accessible or non-accessible, it was required to test and validate the application of innovative survey solutions.

Every catastrophic event that causes human losses, partially or totally destroys our heritage buildings and that puts critical infrastructures out of order, poses the problem of developing innovative solutions for DM, especially in the early impact and recovery phases, where there is a lack in centralized coordination and in availability of resources and facilities. For what concerns Geomatics studies, particularly, a relevant issue is related to the necessity to organize geo-spatial data at urban scales and to document with a rapid mapping procedure the affected sites. These aspects have of course immediate effects in terms of facilitating all actors involved and helping rescuers of the Civil Protection, supervisors and authorities in the management of the post-catastrophe phases, especially in the first phase of emergency.

In this respect, the study of remote-sensing techniques, together with the development of new sensors and new measures for the 3D data validation, has proved to be of considerable importance in supporting emergency mapping and Building Damage Assessment (BDA) [Gagliolo et al., 2018; Zaragoza et al., 2017]. In cases where it is required to intervene in areas that present problems of security and access, the possibility to define a correct correspondence between rapidity of surveying, accuracy of acquired data and surveying and processing techniques available is a key task. For what concerns the surveying methods, the use of remote-sensing data, such as LiDAR data, GNSS techniques and aerial images, offer a significant approach to BDA after the occurrence of natural or man-made hazard: in this regard, Guida et al. (2018), Vetrivel et al. (2018), Poli et al. (2017) and Quest et al. (2016) have offered interesting recent examples of application.
Moreover, the UAVs, also known as drones, are becoming more and more used in emergency mapping and management, as they represent a powerful solution for rapid survey of damaged areas and as they allow to have image acquisition of damaged areas without requiring on-site inspections. The extraction and processing of data acquired via UAV allows to obtain, through the application of photogrammetric techniques and through the use of algorithms derived from Structure from Motion (SfM) studies, reliable 3D study models of the affected sites, on the basis of a photographic sequence.

Many researches have shown the effectiveness of validating the use of drones in emergency phases, in particular after seismic events: De Oliveira Silva et al. (2019) propose a procedure to support the design of aid distribution networks in disaster response operations using UAVs and geographic information systems (GIS), referring to the post-disaster area of Duque de Caxias, in the state of Rio de Janeiro, Brazil; Chatzistamatis et al. (2018) underline the importance of combining UAV survey with Terrestrial Laser-Scanning acquisitions for the detection of buildings after the 2017 earthquake in the South of Lesvos island, Greece; Dominici et al. (2016) test the use of drones to the analyses of post-catastrophe scenarios after the seismic event occurred in L'Aquila (Italy), 2009, and they underline, referring to several case studies, the advantages of UAV photogrammetry in terms of:

Safety issues: absence of risk for inspectors;

Possibility to inspect areas with difficult accessibility;

High resolution photograms;

Rapidity in survey and elaboration phases;

Repeatability of test and low cost of survey instruments.

With the aim to employ all different acquisition systems developed in the field of operative survey for the support of damage monitoring and risk management activities in hazardous situations, the Copernicus EMS was developed, starting from year 2012, in the framework of the European Earth-observation program called Copernicus. The EMS program is activated whenever a catastrophic event occurs, by the Civil Protection and other concerned authorities, in order to obtain aerial and in-situ images and to coordinate, based on the acquired geo-spatial data, the disaster response operations in sites that present reduced or no accessibility. The information is produced with a good Level of Detail (LOD) at an urban scale and with information on the location and impact of the event, on the number of affected people and on the extent of damage on buildings and critical infrastructures [Calantropio et al., 2018].

\section{THE CASE STUDY: CASTELLUCCIO DI NORCIA}

\subsection{Description of the study area}

Between August and October 2016, a seismic sequence very heavily struck the villages and the urban areas located along the Apennine ridge crossing the Italian Regions of Umbria, Marche, Lazio and Abruzzi. The seismic sequence started on $24^{\text {th }}$ August 2016, with a struck of 6.00 moment magnitude, followed by an aftershock if $5.4 \mathrm{Mw}$, and it continued on October $26^{\text {th }}$, with two earthquakes of $5.40 \mathrm{M}_{\mathrm{w}}$ and $5.90 \mathrm{M}_{\mathrm{w}}$ respectively. Then, another seismic event of this sequence occurred on $30^{\text {th }}$ October, at 06:40:17 UTC, with a value of moment magnitude of $6.50 \mathrm{M}_{\mathrm{w}}$ [INGV, 2016]. This last earthquake provoked no casualties but caused several damages and collapses on the built heritage, in an area that has been characterized, all over the years, by high intensity of seismic events. Figure 1 illustrates the main earthquakes that occurred in the area of the Apennine chain, from year 1000 to year 2016, with a value of magnitude greater than or equal to 4 (earthquakes with magnitude value below 4 are 
considered not of engineering interest), according to the crosscheck of data provided by the Italian catalogue of INGV, the Database ISIDe [ISIDe, 2016] and the Italian Accelerometric Archive ITACA [Luzi et al., 2017].

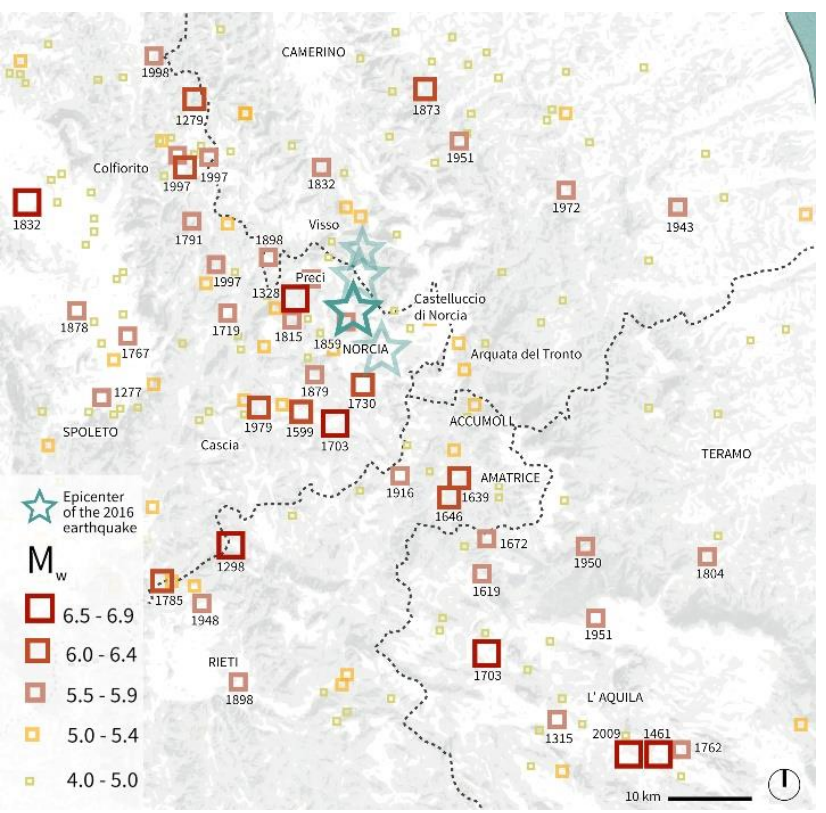

Figure 1. Historical earthquakes of the area. The blue stars indicate the epicenters of the 2016 seismic events.

In the village of Castelluccio di Norcia, located at the easternmost tip of Region Umbria, at an altitude of 1452 meters above sea level and included within the Municipality of Norcia, the main Church and its bell tower registered considerable damage after the first shock of August $24^{\text {th }}$, but it was in the wake of the earthquake of October $30^{\text {th }}$ that a wider extent of damage was observed: the violence of this last strongest event, in fact, razed to the ground almost the $60 \%$ of the buildings of the hamlet.

\subsection{First DDE method: prior information and UAV-based survey}

After the two earthquakes of August and October respectively, the Fire Brigade and the Civil Protection flew over Castelluccio via UAVs, in order to carry out an aerial reconnaissance of the village. The result of the aerial inspection and acquisition campaigns are in terms of videos, showing the state of damage of the village after the two seismic events.

In detail, the recordings made many days after the earthquake of August show the firefighters involved in the activities related to the securing of the main Church of the village, and in particular to the reduction of structural criticality for the bell tower (https://www.youtube.com/watch?v=--BXmgLSdQs). Another video, instead, refers to the state of the village following the most destructive earthquake, which occurred in October; the acquisitions, which describe a circular route around the village, show the desolate village buried all over by heaps of rubble (https://www.youtube.com/watch? $v=18165 \mathrm{r} 3 \mathrm{uh} 8 \& \mathrm{t}=2 \mathrm{~s}$ ).

Both the videos recorded in the framework of the operations carried out by the Fire Brigade are currently available and downloadable on the web, and they give a general and overall view of Castelluccio di Norcia after the seismic events.

In light of the above, even though originally not recorded for specific survey purposes, these videos revealed to be useful for the assessment of the state and extension of damage after the disruptive event of October: through the analysis of the aerial surveys, and precisely through the extraction of frames from the videos recorded, and thanks to the possibilities offered by $3 \mathrm{D}$ photogrammetric reconstruction, it was possible to obtain two complete 3D models of Castelluccio, assessing the situation of the village after the two seismic events.

Since the damage on buildings after the earthquake of August $24^{\text {th }}$ was very low, the model obtained through the elaboration of data from the first video was used to study the layout of the village before the strongest and most disruptive shock of October. Through the comparison of the two 3D study models obtained (Figure 2 and 3), and by deriving the entity of partial and total collapses, a DDE map was constructed.

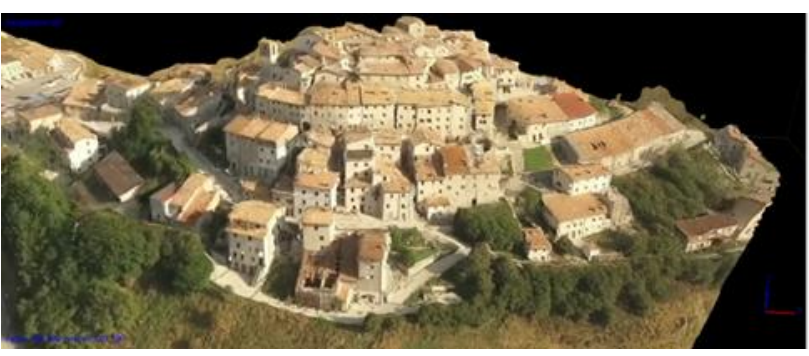

Figure 2. 3D model of Castelluccio before the earthquake

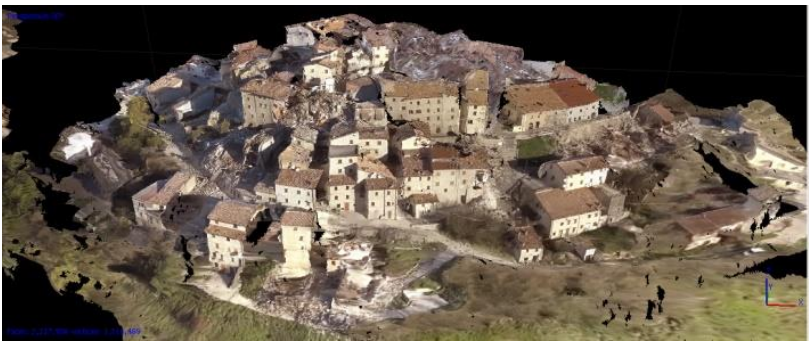

Figure 3. 3D model of Castelluccio after the earthquake

The workflow of the process for this first DDE method is synthetized in Figure 4 and is described in detail below:

\section{Acquisition phase}

The videos recorded by the Fire Brigade were downloaded from the internet, to be used for the generation of the two 3D study models. Since the videos were acquired on the net, it was not possible to provide information on the geometrical characteristics or on the specific model of UAV used. Anyway, from the properties of the videos, which were downloaded in .mp4 and .wmv formats, a display resolution of $1280 \times 720 \mathrm{px}$ was detected, corresponding to an aspect ratio of 16:9. In the first acquisition phase, in addition to the videos related to year 2016 and recorded in the framework of the seismic events, it was possible to acquire a series of data, in .dwg format, relating to the in situ survey campaigns carried out by the Umbria Region few years before the earthquake. In 2004, in fact, the Direction of territorial policies, environment and infrastructures of the Umbria region (in Italian: Direzione delle politiche territoriali, ambiente e infrastrutture della Regione Umbria) realized a series of aerial acquisitions, with a WildRC/30 camera, in order to provide a basic cartography of the regional areas. The technical maps resulting from these survey campaign, geo-referenced in a Gauss-Boaga reference system, can be downloaded on the website geoportal.regione.umbria.it. Through this site, a technical map in scale 1:500 was detected in a three-dimensional vector format for the village of Castelluccio di Norcia. The detailed features of this map are listed in Table 1.

2. Data processing.

The subsequent phase begun with extracting the frames from each video, with a mean value of one frame every two seconds; 
each frame had a digital photo resolution of $96 \mathrm{dpi}$ and a value of bit depth of 32 .

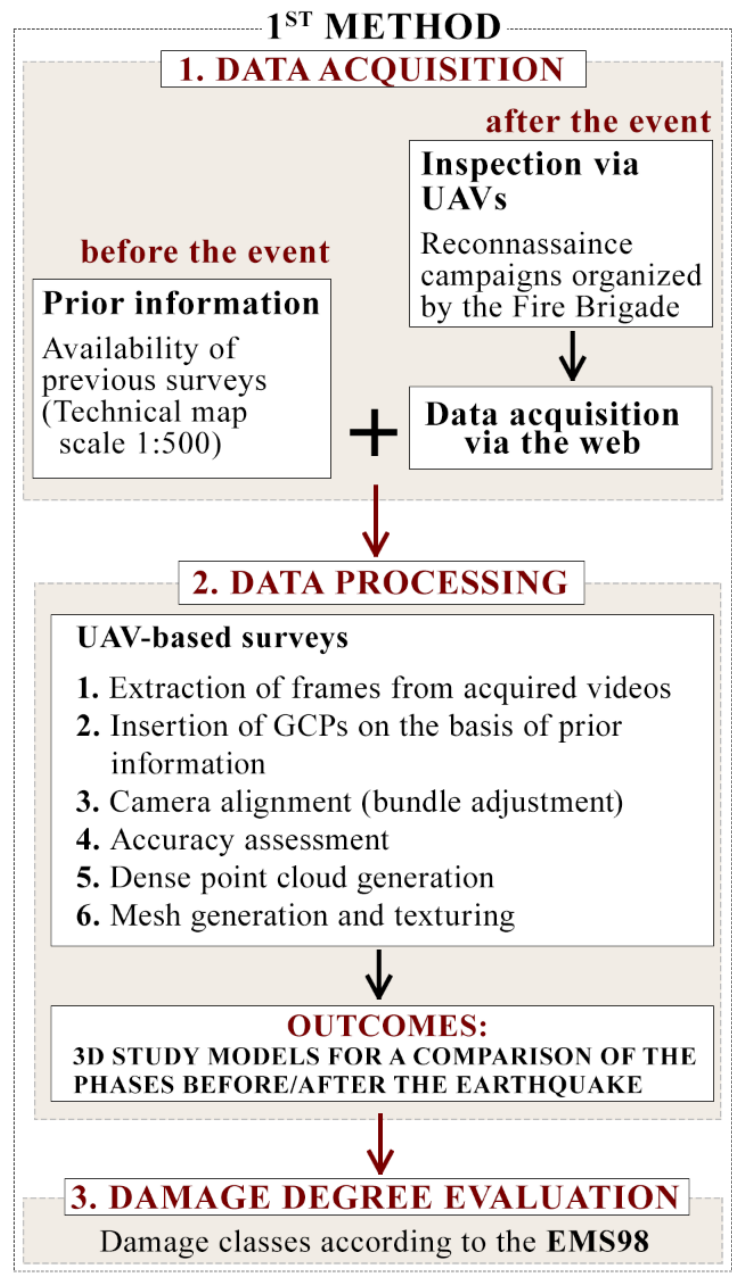

Figure 4. Workflow for DDE map for the $1^{\text {st }}$ method

\begin{tabular}{|l|l|}
\hline Cartographic layout and publication - Year & 2004 \\
\hline Aerial shot - Year & 2003 \\
\hline Aerial shot - Camera & Wild RC/30 \\
\hline Aerial shot - Relative average flight rate & $500 \mathrm{~m}$ \\
\hline Scale & $1: 500$ \\
\hline
\end{tabular}

Table 1. Prior information: data on the technical map (CTR) of Castelluccio provided by Region Umbria

Afterwards, the frames were inserted in a software allowing for the photogrammetric processing of digital images and 3D spatial data generation. In the process of bundle adjustment, the common points in subsequent photos were recognized (the so-called tie points), after having determined the position of the cameras and the camera parameters of calibration.

Furthermore, for a correct orientation and a proper scale of the 3D model, an adequate number of Ground-Control Points (GCPs) was added (Figure 5 and 6). Particularly, due to the availability of the technical map of Castelluccio dated back to 2004, it was possible to assign known coordinates to the GCPs. This expedient allowed to enhance and implement the accuracy of the model and to obtain a geo-referenced survey, based on the prior information available on the area.

The maximum value of root mean square error for $\mathrm{X}, \mathrm{Y}$ coordinates on a frame for a GCP location was set at 3 pixels.

Table 2 shows the maximum and minimum pixel error assessed in the calculation.

\begin{tabular}{|l|l|}
\hline Maximum pixel error assessed & 2.971 \\
\hline Minimum pixel error assessed & 1.094 \\
\hline
\end{tabular}

Table 2. Minimum and maximum root mean square error for $\mathrm{X}$, $\mathrm{Y}$ coordinates on an image for a GCP location

Expressed in meters, the tolerated error was set at $0.4 \mathrm{~m}$ in plan (root mean square error for a GCP location for $\mathrm{X}$ and $\mathrm{Y}$ coordinates) and $0.4 \mathrm{~m}$ in altimetry (error for a GCP location for $\mathrm{Z}$ coordinates). It has to be noted that these values are in total compliance with the tolerances on the precision standards established by the Italian legislation, relating to the drafting of the Italian technical maps in scale 1:500 -that is the scale of the technical map considered as prior information for the georeferencing of the model [WG03 Intesa GIS, 2001].

After this phase, the dense point clouds were generated for each model, and, based on the point cloud, the software can reconstruct a polygonal model - mesh, and a texture atlas.

With the integration of results of ground-based surveys carried out in the past and containing geo-referenced data, the accuracy of the two models was implemented and enhanced: the final 3D models allowed to compare the configuration of Castelluccio before and after the earthquake of October 2016.

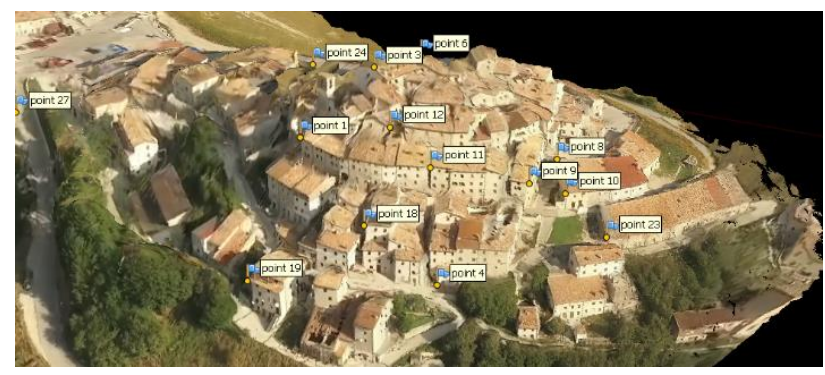

Figure 5. Position of GCPs in the pre-earthquake model

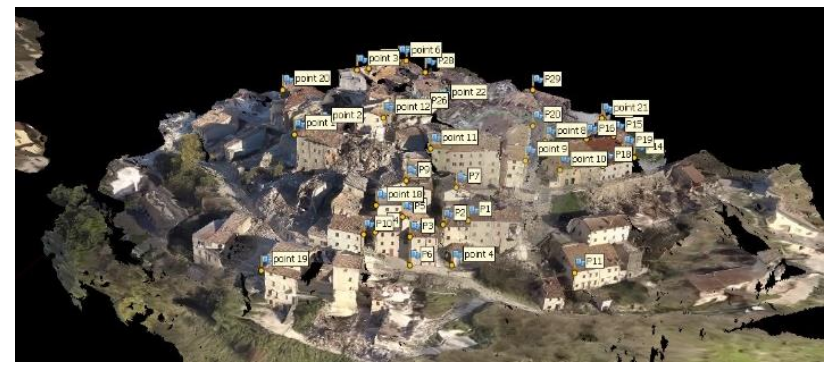

Figure 6. Position of GCPs in the post-earthquake model

3. DDE.

The comparison between the two resulting models, showing respectively the pre- and post-earthquake configurations of the village, was performed in the software CloudCompare, which is fitted out with a specific tool allowing to compute the distances between the two mesh models.

The outcomes of the computation are shown in Figure 7 (below): distances between the two models higher than $0.9 \mathrm{~m}$ allow to identify to collapsed buildings; distances between 0.4 and $0.89 \mathrm{~m}$ correspond to intermediate levels of damage; distances lower than $0.4 \mathrm{~m}$ are in compliance with the error of representation of the technical map and identify no damage. By observing this graphical comparison, a map assessing the level of damage was constructed; in particular, each building was classified based on the distinction provided by the European Macro-seismic Intensity Scale EMS98 [Grünthal, 1998], defining six damage levels, from level DL0 (no damage) up to DL5 (total collapse) (Figure 8, below). It has to be noted that, since kind of survey is based on videos that were not specifically and originally recorded for 
survey purposes, many buildings were not clearly visible in the 3D study models recorded by the Civil Protection, thus it was not possible to assess their damage class; these buildings are coloured up in grey, corresponding to "no data available".

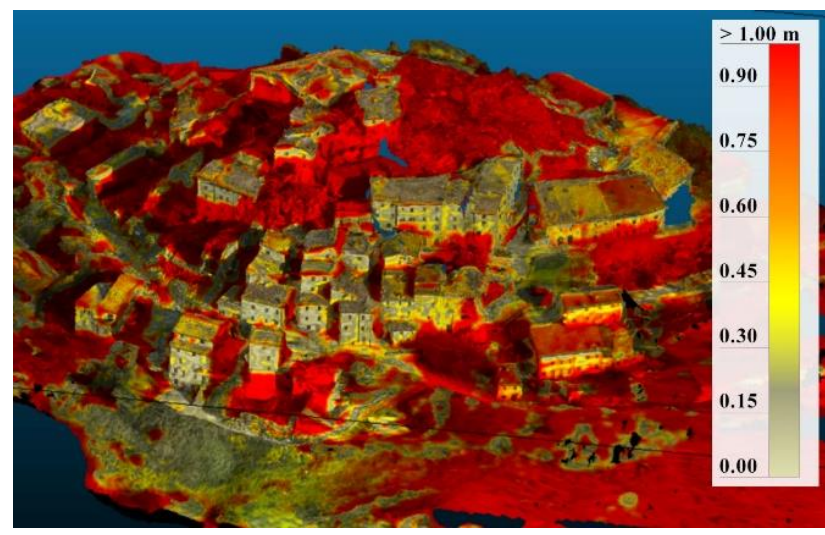

Fig. 7 Cloud-to-mesh comparison: computed distances

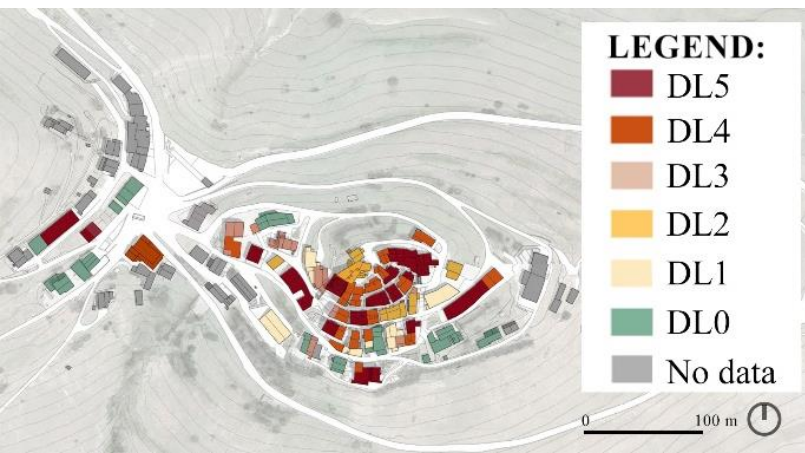

Figure 8. DDE map assessed through the first method.

\subsection{Second DDE method: COPERNICUS EMS Maps}

Besides the results of the first DDE method proposed, in the framework of post-seismic studies in the area of Castelluccio di Norcia, another similar map was constructed by [Calantropio et al., 2018]. Immediately after the earthquake, in fact, the Italian Department of Civil Protection strongly asked for the activation of the COPERNICUS EMS project.

The workflow for the DDE (Figure 9), in this case, presented many differences from the one illustrated in Figure 4:

1. Acquisition phase.

The rapid mapping of geospatial data is based on highresolution satellite imagery and available in situ (on-site) or open source information. Different acquisition systems were therefore implied: UAVs, close-range photogrammetry, LiDAR and SLAM -based mapping.

2. Data processing.

As in case 1, the procedure is based on: bundle adjustment, dense point-cloud generation, mesh construction and texturing; however, the difference is that in this case, due to the availability of numerous sets of data, it was necessary to operate with georeferencing strategies, blocks orientations and multi-temporal co-registration solutions. For more information on these aspects, see [Calantropio et al., 2018].

3. DDE.

The outcome of the EMS activation procedure is a damage level map (Figure 10) that is of course more accurate and precise than the one obtained through the application of the first method proposed, since it is the result of a study based on different survey acquisition systems. The map in this case classifies four different levels of damage on the buildings of the village, distinguishing between destroyed, highly damaged, moderately damaged and negligible to slight damage areas.

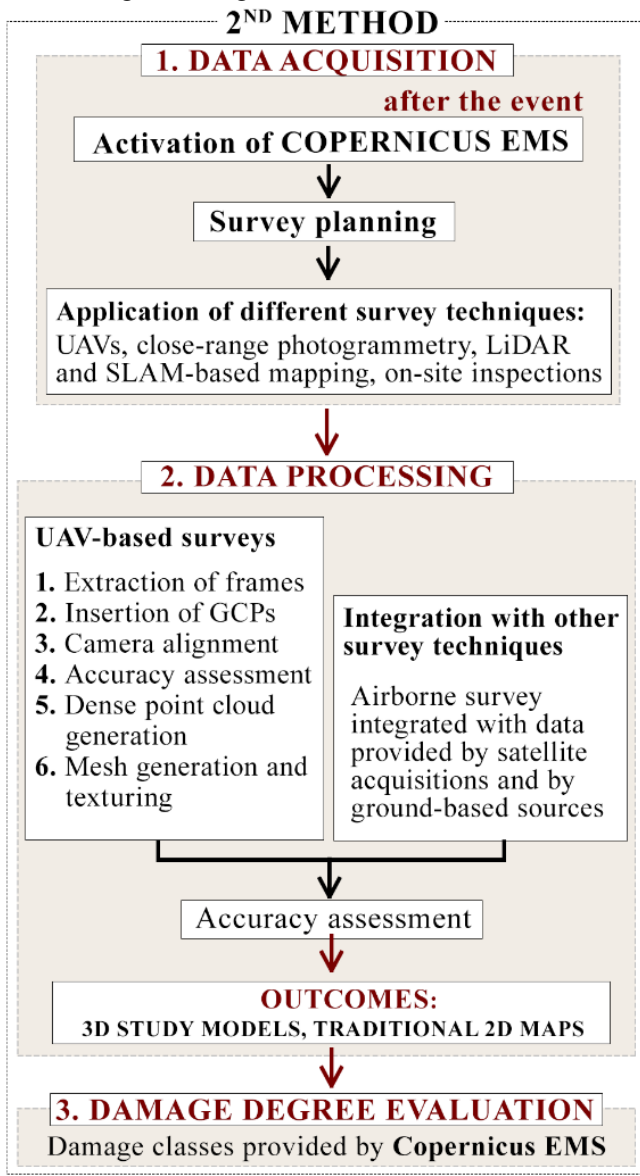

Figure 9. Workflow for the DDE map for the $2^{\text {nd }}$ method.

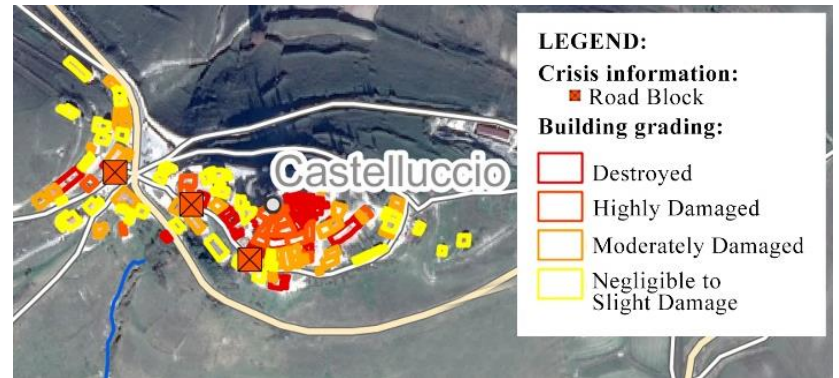

Figure 10. Copernicus EMS (@ 2016 European Union),

[EMSR190] Castelluccio Grading Overview Monit 01

\subsection{Comparison between first and second method}

All above-mentioned methods have as result a grading product, in form of a map showing the spatial distribution and extent of damage. For the comparison of the two maps, it was necessary to create a correspondence between the classification of damage levels (DL) provided by the first method and established based on the EMS98 and the grading map used by Copernicus EMS. Table 3 (below) identifies the compliance in the categorization provided by the two methods. In order to establish the goodness and applicability of the first method, in comparison with the one resulting from COPERNICUS project survey campaigns, it was necessary to evaluate the correspondence between the two different DDE maps, in terms of damage level assessed.

Figure 11 (below) graphically shows the results of the comparison between the two methods, highlighting the cases in which the classification of the damage level corresponds and the 


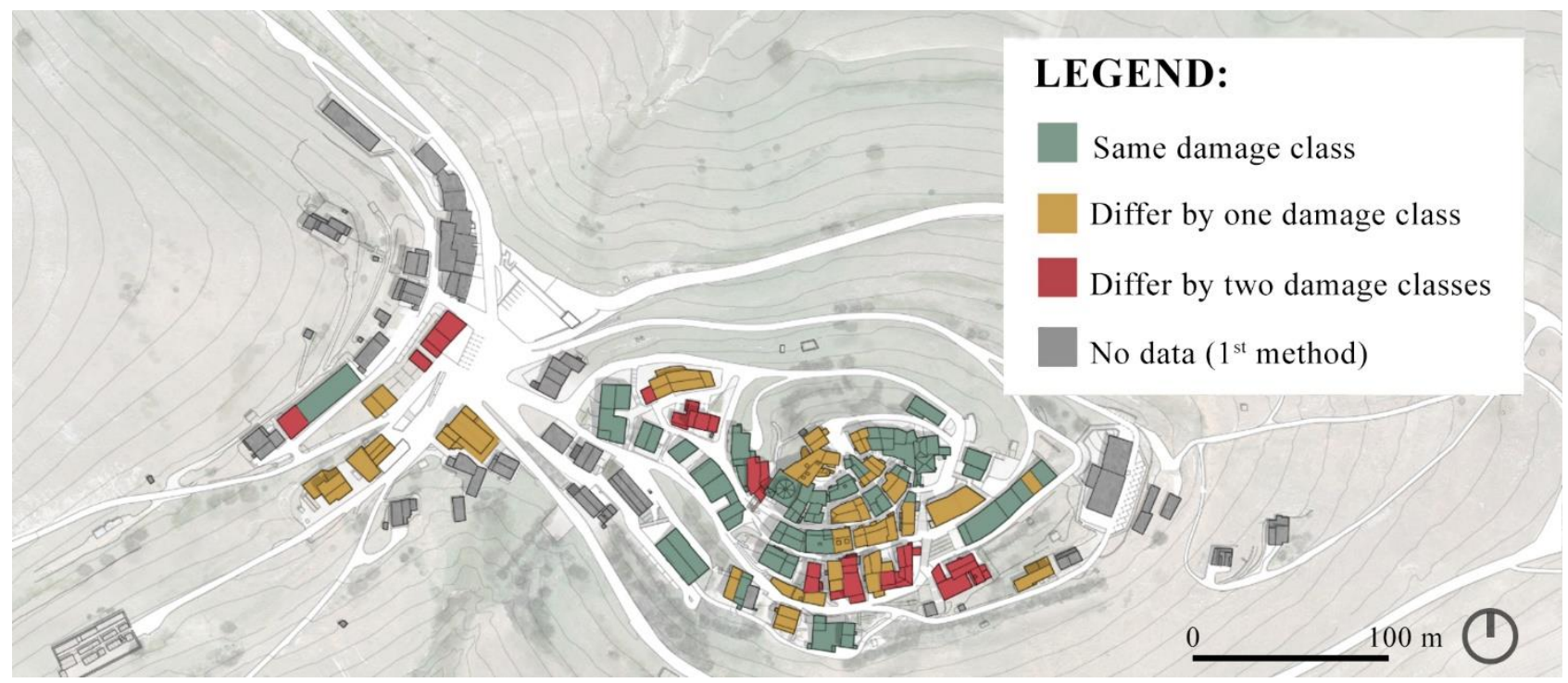

Figure 11. Graphical comparison between the two DDE methods

\begin{tabular}{|l|l|}
\hline $\begin{array}{l}\text { First method } \\
\text { (EMS98) }\end{array}$ & $\begin{array}{l}\text { Second method } \\
\text { (Copernicus EMS98) }\end{array}$ \\
\hline DL0 & Absence of damage \\
\hline $\begin{array}{l}\text { DL1: Negligible to slight } \\
\text { damage }\end{array}$ & Negligible to slight damage \\
\hline DL2: Moderate damage & Moderately damaged \\
\hline $\begin{array}{l}\text { DL3: Substantial to heavy } \\
\text { damage }\end{array}$ & Highly damaged \\
\hline DL4: Very heavy damage & Destroyed \\
\hline DL5: Destroyed & D
\end{tabular}

Table 3. Comparison between DDEs. DL3 and DL4 (1 ${ }^{\text {st }}$ method) both correspond to the class "highly damaged" $\left(2^{\text {nd }}\right.$ method).

cases in which the assessment differs, by one or two classes of damage respectively, from one method to another.

The buildings that are colored in grey in Figure 11 were not clearly visible in the $3 \mathrm{D}$ models assessed through the first method, thus they were not considered in the comparison between the two DDEs. However, by excluding the cases of these buildings where there is a lack of data, the analysis of the correspondence for the rest of the buildings -the ones on which, based on the UAV-based survey only, a certain class of damage could be assessed and assigned, interesting comments can be reported. Looking at the graph of Figure 12, in fact, it is possible to observe that, for the $47 \%$ of the surface occupied by these buildings, the same class of damage was assessed in both methods. Instead, for the $38 \%$, the DDE differed by one class between the first and the second method, and for the remaining $15 \%$ it differed by two classes.

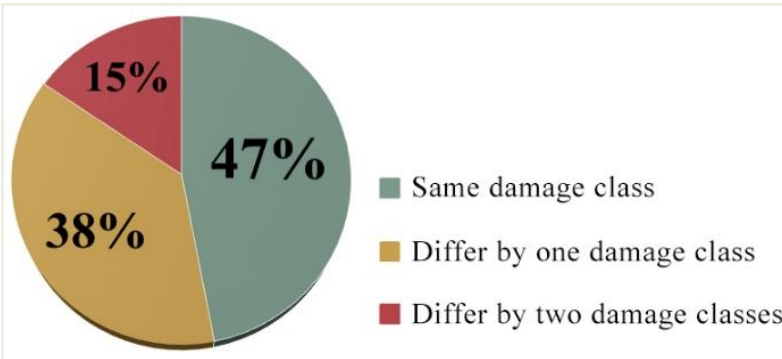

Figure 12. Comparison, in terms of surface occupied by buildings, between the two DDE methods

\section{RESULTS}

The results of the comparison between the first and the second method proposed are thorough and satisfying and allow to establish a remarkable correspondence between the different damage maps constructed. Firstly, it has to be noted that the first method, even if based on data downloaded via the web and therefore at lower resolution, and even if acquired with a more rapid evaluation procedure not providing for ground-based surveys, leads to the construction of damage level maps that are reliable and realistic. Referring to the cases in which a high level of destruction is detected after a catastrophic event, the results of this simplified method appear satisfactory and useful in the process of management and monitoring of hazards: by way of demonstration, Figure 13 shows that, among the buildings for which the same level of damage was assessed both with the application of the first method than with the application of the second method, $58 \%$ of them belonged to the class of "destroyed" buildings and $26 \%$ of them belonged to the class of "highly damaged" buildings. The fact that the higher correspondences in the DDE are in the cases of more consistent damage on buildings implies that, for most disrupted areas, the first method, even if based on a faster and more simplified procedure, can be extremely helpful in post-disaster management, allowing stakeholders and Civil Protection to organize disaster rescue operations in areas that, after the occurrence of natural or manmade hazards, present safety issues or are difficult to access.

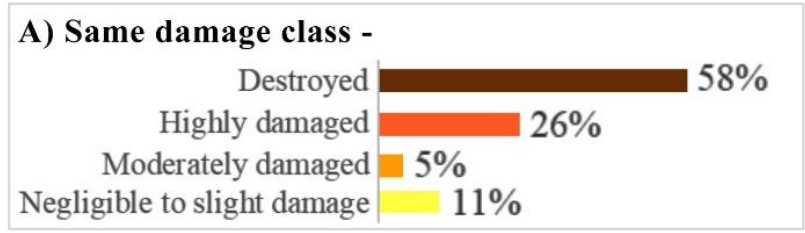

Figure 13. Percentage of buildings that had same damage class assessed in both $1^{\text {st }}$ and $2^{\text {nd }}$ method.

Looking at Figure 14 (below), anyway, it is possible to observe that the cases in which the DDE differed by one damage class are for the $41 \%$ the cases in which the buildings -according to the more accurate procedure of DDE based on the second method, were classified as "moderately damaged" and for the $29 \%$ the cases in which the buildings were classified as "negligible to slight damage". 


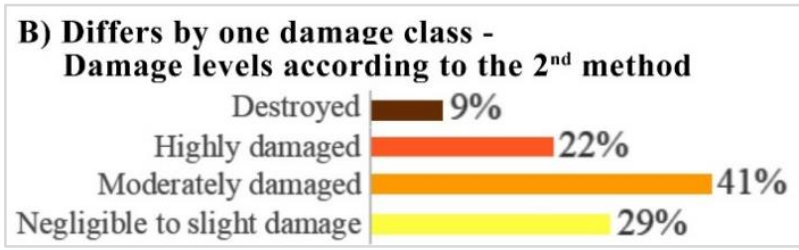

Figure 14. Difference by one damage class between the two DDEs: percentage of buildings that had a certain damage class according to the assessment of the $2^{\text {nd }}$ method.

Analogously, Figure 15 shows the cases in which the DDE differed by two damage classes: in these cases, according to the more reliable second method, the $67 \%$ of the buildings were assessed as "moderately damaged", and the $33 \%$ as "negligible to slight damage".

\section{C) Differs by two damage classes - \\ Damage levels according to the $2^{\text {nd }}$ method Destroyed - \\ Highly damaged - \\ Moderately damaged \\ Negligible to slight damage \\ $33 \%$

Figure 15. Difference by two damage classes between the two DDEs: percentage of buildings that had a certain damage class according to the assessment of the $2^{\text {nd }}$ method.

By these results, it can be noted that the most significant differences that, as a matter of fact, are recorded starting from the comparison between the two study method are the ones that concern the buildings that have suffered minor damage as a result of the earthquake occurrence, thus the first method is not completely passing when areas present a lower and less extensive level of damage.

Even if in these cases it should be supported by further and more accurate survey investigations, the first method could be helpful in the management of the first emergency cases, when, after a disruptive event, a rapid damage detection after a catastrophic event is required, in order to decide, as a preliminary and faster evaluation, which areas are accessible or non-accessible by rescuers and authorities for putting into practice saving and securing operation. In this sense, it can be noted that a simplified procedure, based on prior information on the damaged area and on immediate aerial data available on the net and accessible to every user, as the first method is, even if not completely applicable to the cases of less damaged areas, could offer a support for the implied institutions, in terms of information on catastrophes and disaster rescue management and it can offer anyhow a crucial aid in rapid damage detection after a catastrophic event.

\section{CONCLUSIONS}

The paper compared two different workflows for deriving the entity of partial and total collapses and for evaluating the damage degree after a catastrophic event.

The observed results of the comparison show that a simplified procedure, based on immediate aerial data and on information available on the net and accessible to every user, can be helpful and fundamental in building damage assessment and can offer a crucial aid in rapid damage detection after a catastrophic event. As part of the topographic survey, access to spatial data on a given built area allows to reconstruct, using the latest techniques of SfM and MultiView Stereo (MVS), derived from Computer Vision, three-dimensional models that can be suitable in damage detection for the purposes of analysis, management and monitoring of post-catastrophe scenarios. Thus, whenever a catastrophic event occurs that partially or totally destroys the places of the cultural heritage, it is possible, by acquiring information on the place affected by the event and by applying a faster procedure based on UAV survey and on the integration with prior information on the damaged site, to digitally reconstruct in a 3D view the structure of the area respectively in the pre- and post- catastrophe phases. From this point of view, digital information technologies can represent a powerful support tool in the management of natural hazards and in the studies on the event's lifecycle. In the framework of the numerous possibilities offered by recent advances in the field of geomatics applied to disaster management, a further development of this study could concern the possibility to detect an automated procedure for the assessment of the damage classes on buildings after a disruptive event, based on the direct extraction of information from the software analysis of 3D models. Indeed, kind of process could promptly allow to have an assessment of the damage level on buildings: the comparison between the preand post-catastrophe phases, based on the 3D models, could be made in terms of volumes, and in this sense it would be interesting to develop an algorithm allowing to automatically detect the damage level on buildings and provide the results in a raster map; these data, if inserted and made available in a Geographic Information System, could allow the management of emergency phases by authorities and Civil Protection to be developed more completely and rapidly.

\section{ACKNOWLEDGEMENTS}

The following paper partly shows the results of a thesis work, developed by Valeria Croce on the area of Castelluccio di Norcia, involving as supervisors M. G. Bevilacqua, E. Bascherini, L. Lanini and I. Martínez-Espejo Zaragoza, from the University of Pisa, Italy, and D. Diamantidis from OTH Regensburg, Germany.

\section{REFERENCES}

Alicandro, M., Rotilio, M., 2019. UAV Photogrammetry for resilience management in reconstruction plan of urban historical centres after seismic events. A case study. In: ISPRS Int. Arch. Photogramm. Remote Sens. Spat. Inf. Sci., Vol. XLII-2/W11, pp. 55-61,

doi.org/10.5194/isprs-archives-XLII-2-W11-55-2019.

Bevilacqua, M. G., Caroti, G., Piemonte, A., Terranova, A. A., 2018. Digital technology and Mechatronic Systems for the Architectural 3D Metric Survey, Mechatronics for Cultural Heritage and Civil Engineering, 92, pp. 161-180.

Boccardo, P., Giulio Tonolo, F., 2015. Remote Sensing Role in Emergency Mapping for Disaster Response, Engineering Geology for Society and Territory, 5, pp. 17-24. doi.org/10.1007/978-3-319-09048-1_3.

Calantropio, A., Chiabrando, F., Sammartano, G. Spanò, A.; Losè, L. T., 2018. UAV strategies validation and remote sensing data for damage assessment in post-disaster scenarios. In: ISPRS Int. Arch. Photogramm. Remote Sens. Spat. Inf. Sci., Vol. XLII3-W4, pp. 121-128,

doi.org/10.5194/isprs-archives-XLII-3-W4-121-2018.

Caroti, G., Zaragoza, I.M.-E., Piemonte, A., 2015. Accuracy assessment in structure from motion 3D reconstruction from UAV-born images: The influence of the data processing 
methods. In: ISPRS Int. Arch. Photogramm. Remote Sens. Spat. Inf. Sci., Vol. XL-1-W4, pp.103-109,

doi.org/10.5194/ isprsarchives-XL-1-W4-103-2015.

Caroti, G., Piemonte, A., Pieracci, Y., 2017a. UAV-borne photogrammetric survey as USAR firefighter teams support. In: Lecture Notes in Computer Science, 10407 LNCS, pp. 3-15, doi.org/10.1007/978-3-319-62401-3_1.

Caroti, G., Piemonte, A., Nespoli, R., 2017b. UAV-Borne photogrammetry: A low cost 3D surveying methodology for cartographic update. MATEC Web of Conferences, doi.org/10.1051/matecconf/201712009005.

Caroti, G., Piemonte, A., Zaragoza, I.M.-E., Brambilla, G., 2018a. Indoor photogrammetry Using UAVs with protective structures: Issues and precision tests. In: ISPRS Int. Arch. Photogramm. Remote Sens. Spat. Inf. Sci., XLII-3-W4, pp. 137142 ,

doi.org/10.5194/isprs-archives-XLII-3-W4-137-2018.

Caroti, G., Piemonte, A., Pieracci, Y., 2018b. Low-altitude UAV-borne remote sensing in dunes environment: Shoreline monitoring and coastal resilience. In: Lecture Notes in Computer Science, 10964 LNCS, pp. 281-293,

doi.org./10.1007/978-3-319-95174-4_23.

Chatzistamatis, S., Kalaitzis, P. ; Chaidas, K., Chatzitheodorou C., Papadopoulou, E. E., Tataris, G., Soulakellis, N., 2018. Fusion of TLS and UAV Photogrammetry Data for PostEarthquake 3D Modeling of a Cultural Heritage Church. In: ISPRS Int. Arch. Photogramm. Remote Sens. Spat. Inf. Sci., Vol. XLII-3-W4, pp. 143-50,

doi.org/10.5194/isprs-archives-XLII-3-W4-143-2018.

Copernicus Emergency Management Service, 2016. EMSR190, copernicus.eu/sites/default/files/documents/Copernicus_Factshe ets/Copernicus_EmergencyMonitoring_Feb2017.pdf.

Croce, V., Martínez-Espejo Zaragoza, I., 2018. UAV-based 3D Photogrammetry for post-Earthquake Studies on Seismic damaged Cities - A Case Study: Castelluccio di Norcia. In: IMSCI 2018 - $12^{\text {th }}$ International Multi-Conference on Society, Cybernetics and Informatics, Proceedings, Vol.2, p.79-84.

De Oliveira Silva, L., De Mello Bandeira, R. A., Barcellos Gouvêa Campos, V., 2019. Proposal to Planning Facility Location Using UAV and Geographic Information Systems in a Post-Disaster Scenario, International Journal of Disaster Risk Reduction, 36, pp. 1-11,

https://doi.org/10.1016/j.ijdrr.2019.101080.

Dominici, D., Alicandro, M., Massimi, V., 2016. UAV Photogrammetry in the Post-Earthquake Scenario: Case Studies in L'Aquila. In: Geomatics, Natural Hazards and Risk 8 (1): 87 103. https://doi.org/10.1080/19475705.2016.1176605.

Gagliolo, S., Fagandini, R., Passoni, D., Federici, B., Ferrando, I., Pagliari, D., Pinto, L., Sguerso, D., 2018. Parameter Optimization for Creating Reliable Photogrammetric Models in Emergency Scenarios. In: Applied Geomatics 10 (4), 501-14. https://doi.org/10.1007/s12518-018-0224-4.

Grünthal G., European Macroseismic Scale 1998 (EMS-98), 1998. Center Europèen de Géodynamique et de Séismologie, Luxembourg.
Gruppo di lavoro INGV sul terremoto in Centro Italia, 2016. Summary report on the October 30th, 2016 earthquake in Central Italy. https://doi:10.5281/zenodo.166238

Guida, L., Boccardo, P., Donevski, I., Lo Schiavo, L., Molinari, M. E., Monti-Guarnieri, A., Oxoli, D., Brovelli, M. A., 2018. Post-disaster damage assessment through coherent change detection on SAR Imagery. In: ISPRS Int. Arch. Photogramm. Remote Sens. Spat. Inf. Sci., Vol. XLII-3, pp. 431-436, doi.org/10.5194/isprs-archives-XLII-3-431-2018.

Havas, C., Resch, B., Francalanci, C., Pernici, B., Scalia, G., Fernandez-Marquez, J.L., Van Achte, T., Zeug, G., Mondardini, M.R.R., Grandoni, D., Kirsch, B., Kalas, M., Lorini, V., Rüping, S., 2017. E2mC: Improving Emergency Management Service Practice through Social Media and Crowdsourcing Analysis in Near Real Time, Sensors 2017, 17, 2766.

ISIDe working group, 2016. version 1.0, DOI: 10.13127/ISIDe.

Luzi, L., Pacor, F., Puglia, R., 2017. Italian Accelerometric Archive v 2.3. Istituto Nazionale di Geofisica e Vulcanologia, Dipartimento della Protezione Civile Nazionale. doi: 10.13127/ITACA.2.3.

Quest, W. G., Azzaro, R.., Tertulliani, A., Bernardini, F., Camassi, R., Del Mese, S., Ercolani, E. et al., 2016. The 24 August 2016 Amatrice Earthquake: Macroseismic Survey in the Damage Area and EMS Intensity Assessment, In: Annals of Geophysics, 59, pp. 1-8, doi.org/10.4401/ag-7203.

Poli, D., Moe, K., Legat, K., Toschi, I., Lago, F., Remondino, F., 2017. Use of Vertical Aerial Images for Semi-Oblique Mapping. In: ISPRS Int. Arch. Photogramm. Remote Sens. Spat. Inf. Sci., Vol. XLII-1-W1, pp. 493-98,

doi.org/10.5194/isprs-archives-XLII-1-W1-493-2017.

Remondino, F., Barazzetti, L., Nex, F., Scaioni, M., Sarazzi D., 2016. UAV Photogrammetry for Mapping and 3D Modeling. In: ISPRS Int. Arch. Photogramm. Remote Sens. Spat. Inf. Sci., XXXVIII-1-C22-25-2011, pp. 1-7.,

doi.org/10.5194/isprsarchives-XXXVIII-1-C22-25-2011

Vetrivel, A., Gerke, M., Kerle, N., Nex, F., Vosselman, G., 2018. Disaster damage detection through synergistic use of deep learning and $3 \mathrm{D}$ point cloud features derived from very highresolution oblique aerial images, and multiple-kernel-learning. ISPRS Journal of Photogrammetry and Remote Sensing, 140, pp. 45-59,

doi.org/10.1016/j.isprsjprs.2017.03.001.

WG03 IntesaGIS, 2001. Prescrizioni Tecniche per la produzione di Modelli Digitali del Terreno.

Zaragoza, I.M.-E., Caroti, G., Piemonte, A., Riedel, B., Tengen, D., Niemeier, W., 2017. Structure from motion (SfM) processing of UAV images and combination with terrestrial laser scanning, applied for a 3D-documentation in a hazardous situation. Geomatics, Natural Hazards and Risk, 8 (2), pp.1492-1504. 